\title{
Behavior and Psychology of Daegu Subway Fire Accident in Korea
}

\author{
Chunyang LIANG \\ China University of Mining and Technology (Beijing), \\ Beijing 100083, China \\ Jianping YOU \\ China University of Mining and Technology (Beijing), \\ Beijing 100083, China

\section{Wei JIANG} \\ China University of Mining and Technology (Beijing), \\ Beijing 100083, China
}

\author{
Chenghao YANG \\ China University of Mining and Technology (Beijing), \\ Beijing 100083, China
}

Gui FU

China University of Mining and Technology (Beijing), Beijing 100083, China

\begin{abstract}
This paper was aimed at exploring the unsafe behavior and unsafe psychological status of people in subway fire on the basis of the 24Model and the Health Belief Model. The unsafe acts and habitual behavior causes of Daegu subway fire accident in Korea by 24Model and the unsafe psychological status of passengers in habitual behavior causes by Health Belief Model were analyzed. The results showed those 15 unsafe acts and corresponding habitual behavior and a method for predicting unsafe psychological factors that affect people's escape in subway fire accidents. Health education should increase the perception of the seriousness of the consequences of the subway fire, in order to carry out targeted subway fire self-help escape knowledge dissemination. Although we have made some achievements, there were still some limits, which need to be further explored and improved.
\end{abstract}

Keywords-Safety management; Subway fire; 24Model; Health Belief Model

\section{INTRODUCTION}

The subway is a kind of independent rail transport system and it can deliver passengers quickly, safely, and comfortably, so it has a great role in relieving the traffic pressure in the city, expanding the city space. According to the forecast of SCI Verkehr Company, by 2018 the world will be put into the $4800 \mathrm{~km}$ subway line and by 2025 it will be put into the new line of 5200km [1]. But the subway operating system is vulnerable in the face of fires, terrorism and other disasters. Most of the subway disaster comes from fire [2]. The subway and underground stations are both closed environment, when the fire occurs, the underground temperature rises fast, the fire spreads rapidly and it is easy to produce poisonous smoke. And people are always in a huge panic in the closed environment, so in the subway fire people are not easy to escape and fire rescue is also difficult. Most researchers focus on the analysis of subway operation accidents and construction accidents [3-6] and there are few articles analyze the behavior and psychology in subway fire accidents.

In this paper, we analyzed the Daegu subway fire accident in Korea by 24Model [7-9] and Health Belief Model. This would have a good role in the prevention of subway fire accidents in China and the research about the psychological aspects of people escaping in subway fires.

\section{24MODEL}

The accident occurs at least in an organization. Within the organization, the causes of the accidents are on two levels and four stages, so the model is called 24Model. As a typical modern accident cause theory, the model thinks that the direct causes of the accident are unsafe acts and unsafe conditions and the indirect causes are the unsafe habitual behaviors of organizational members including insufficient safety knowledge, insufficient safety consciousness, poor safety habit, poor safety psychological status and poor safety physiological status. The radical causes are the defects of the safety management system of organizations, and the root causes are the defects of the safety culture of organizations. The model aims to provide a general method for the causation analysis of accidents. On this basis, the causes of Daegu subway fire accident in Korea are analyzed in depth.

\section{ANALYSIS OF THE CAUSE OF ACCIDENT}

\section{A. Overview of the accident}

On February 18, 2003, a fire accident broke out in the Central Road Station at Subway Line 1 in Daegu. The cause of the fire was a 57-year-old passenger who fired a plastic bottle containing gasoline into the sixth carriage. Although the surrounding passengers tried to stop him, the arsonist still threw the bottle in the carriage filled with flammable materials. The gasoline spread and then the fire spread rapidly. After four minutes of the fire, train 1080 entered the station and stopped at the platform opposite the fire train. In order to avoid heavy smoke entering the carriage, the driver of the train 1080 closed the door for about five minutes. During this time, passengers lost their escape time. And the communication system of the station was out of order and the smoke exhaust system was impeded. At this point the control center commanded train 1080 away from the station, but the power supply had been cut off. As the door could not open, passengers in the carriage suffocated. The fire lasted from 9:54 am to 1:38 pm for a total of 3 hours and 26 minutes, resulting in 192 deaths and 147 injuries. The direct economic loss was about 500 billion won (about $\$ 500$ million)[10-11]. 


\section{B. Analysis of unsafe acts}

In general, unsafe acts are made up of different movements produced by different people. According to document [12], the direct cause of the accident in this paper is Kim. The unsafe act of the accident is that Kim ignited the flammable liquid in the plastic bottle with a lighter. Other people associated with the accident include the train driver, the control center staff, design manufacturers, the safety management operator and some passengers who have an impact on accidents or events and events that occur in the event of an accident.

Unsafe acts by other personnel: The control center staff did not prevent train 1080from entering the fire platform. The driver of train 1080 failed to leave the platform in time and the train door was not opened. Most of passengers did not use fire extinguisher and they did not familiar with escape routes. Design manufacturers designed seats with inflammable and decorative materials in train carriages, all closed train windows, the installation of complex doors, defective communication system, the irregular separation distance between platforms and defective exhaust system. The station safety management personnel did not set up enough fire extinguishers, emergency lights and escape route indicator. There was no risk assessment for seats decorated with flammable materials, all closed doors and unlock devices with complex doors, the communication system, the separation distance between platforms and the exhaust system.

\section{HEALTH BeLIEF MODEL FOR PEOPLE'S PSYCHOLOGICAL EVALUATION RECOMMENDATIONS}

Health Belief Model is by far the most widely used in health education and health promotion theory [13]. HBM consists seven theoretical constructs: perceived severity, perceived susceptibility, perceived benefits, perceived barriers, modifying variables, cues to action and self-efficacy. HBM constructs could predict the performance of a healthy behavior [14]. In this accident, passengers' unclear self-help escape knowledge affected the escape in subway fires. Based on the content of Health Belief Model and the literature of predicting human health-related behaviors, the questionnaire was designed to investigate university students' health beliefs about escape and self-help in subway fires and the data was analyzed by SPSS 20.0.

This study was carried out in Beijing with a sample of 300 healthy university students. 18 students filled out the questionnaires incompletely. So the final sample size was $\mathrm{N}=282$ questionnaires analyzed and the response rate was 94.0 percent. The self-administered questionnaire including demographic characteristics and a questionnaire based on HBM constructs were developed for this study. Demographic characteristics included age, gender, level of education, the experience of subway fires, the understanding of fire fighting knowledge and so on. Details of participants were shown in Table 1.The average age of the sample population is 23.6 years old (sample variance is 2.41). The application of Health Belief Model in this study was shown in Table 2. The questionnaire consisted of six dimensions were designed by authors with 17 problems. The derived items were measured on a Likert scale ranging from 1 (strongly disagree) to 5 (strongly agree). To test the reliability, the internal consistency was assessed by using Cronbach's alpha coefficient. In this study, the alpha was 0.746 . In general, an alpha is greater than 0.70 considered satisfactory [15]. Multiple regression analyses were used to predict the HBM constructs for university students' health beliefs about self-help in subway fires. In this study, $\mathrm{p}<.05$ was considered statistically significant.

TABLE I. DEMOGRAPHIC CHARACTERISTICS OF THE PARTICIPANTS

\begin{tabular}{|c|c|c|c|}
\hline Variable & $\operatorname{Mean}(\mathrm{SD})$ & $\mathrm{N}$ & $\%$ \\
\hline Age (years) & $23.6(2.41)$ & & \\
\hline $15-19$ & & 1 & 0.4 \\
\hline $20-24$ & & 197 & 69.9 \\
\hline $25-29$ & & 75 & 26.6 \\
\hline $30-34$ & & 9 & 3.2 \\
\hline \multicolumn{4}{|l|}{ Sex } \\
\hline Male & & 156 & 55.3 \\
\hline Female & & 126 & 44.7 \\
\hline \multicolumn{4}{|l|}{$\begin{array}{l}\text { Education } \\
\text { background }\end{array}$} \\
\hline Undergraduates & & 105 & 37.2 \\
\hline Postgraduates & & 149 & 52.8 \\
\hline Doctors & & 28 & 9.9 \\
\hline \multicolumn{4}{|l|}{$\begin{array}{l}\text { Often travel by } \\
\text { subway }\end{array}$} \\
\hline Yes & & 215 & 76.2 \\
\hline No & & 67 & 23.8 \\
\hline \multicolumn{4}{|l|}{$\begin{array}{l}\text { Experienced a } \\
\text { subway fire }\end{array}$} \\
\hline Yes & & 3 & 1.1 \\
\hline No & & 279 & 98.9 \\
\hline \multicolumn{4}{|l|}{$\begin{array}{l}\text { Self-help escape } \\
\text { knowledge in } \\
\text { subway fire }\end{array}$} \\
\hline Yes & & 62 & 22 \\
\hline No & & 220 & 78 \\
\hline
\end{tabular}


TABLE II. The APPlicAtion of HeAlth BELIEF MOdEL IN THE STUDY

\begin{tabular}{|c|c|l|c|c|}
\hline $\begin{array}{c}\text { Variable } \\
\begin{array}{c}\text { perceived } \\
\text { susceptibility }\end{array}\end{array}$ & Items & \multicolumn{1}{|c|}{ An example } & Score range & $\alpha$ \\
\hline $\begin{array}{c}\text { The probability of encountering a subway fire accident is } \\
\text { very high. } \\
\text { serceived }\end{array}$ & 5 & $\begin{array}{l}\text { Being injured in a subway fire accident could lead to } \\
\text { long-standing problems. }\end{array}$ & $12 \sim 25$ & 0.529 \\
\hline $\begin{array}{c}\text { perceived } \\
\text { benefits }\end{array}$ & 3 & $\begin{array}{l}\text { Knowing the subway safety signs and facilities can help me } \\
\text { escape in the subway fire accident. }\end{array}$ & $5 \sim 15$ & 0.753 \\
\hline $\begin{array}{c}\text { perceived } \\
\text { barriers }\end{array}$ & 2 & $\begin{array}{l}\text { Attending lectures about the knowledge of self-rescue in } \\
\text { subway fire will interfere with my activities. }\end{array}$ & $2 \sim 10$ & 0.686 \\
\hline self-efficacy & 2 & $\begin{array}{l}\text { I am fully confident in helping myself by self-help escape } \\
\text { knowledge in subway fires. }\end{array}$ & $2 \sim 10$ & 0.739 \\
\hline cues to action & 2 & $\begin{array}{l}\text { Safe evacuation signs and emergency lights can help you } \\
\text { escape in the dark when the station is out of power. }\end{array}$ & $6 \sim 20$ & 0.672 \\
\hline
\end{tabular}

TABLE III. LOGICAL REGRESSION ANALYSIS ON SUBWAYFIRE SELF-HELP ESCAPE KNOWLEDGE

\begin{tabular}{|c|c|c|c|c|}
\hline Variable & $\mathrm{B}$ & $\mathrm{OR}$ & $95 \% \mathrm{CI}$ & $\mathrm{p}$ \\
\hline susceptibility & -0.469 & 0.626 & $0.397-0.988$ & $0.044<0.05$ \\
\hline severity & 0.976 & 2.763 & $1.490-5.121$ & $0.001<0.01$ \\
\hline benefits & -0.544 & 0.580 & $0.296-1.137$ & 0.113 \\
\hline barriers & 0.188 & 1.207 & $0.848-1.719$ & 0.296 \\
\hline self-efficacy & -0.380 & 0.684 & $0.453-1.032$ & 0.070 \\
\hline cues to action & -0.536 & 0.585 & $0.317-1.083$ & 0.088 \\
\hline
\end{tabular}

Logical regression analysis was shown in Table 3. It was showed the relationship between the dimensions of Health Belief Model and the understanding of self-help knowledge in subway fires. It could be seen that perceived severity and perceived sensitivity significantly affected people's understanding of self-help escape knowledge in subway fires. The contribution of perceived severity to the prediction of understanding of the self-help escape knowledge in subway fires was more significant than the contribution of perceived sensitivity. And with the increase of perceived severity, more university students who know the self-help escape knowledge in subway fire have increased. While with the increase of perceived sensitivity, the number of university students who know self-help escape knowledge in subway fire is reduced. The result is that people perceive the more serious the consequences of subway fire, the more people understand the subway fire escape and self-rescue knowledge. However, people's perception to subway fires may be affected by many factors such as the current subway safety in China is in a good condition and these may not cause much attention to subway fires. So to some extent, people may have the luck to think that subway fire accidents can hardly happen and never happen to themselves.

\section{CONCLUSION}

(1) According to 24Model, the causes of unsafe acts and habitual behavior were analyzed. Based on Health Belief Model, the perception of self-help escape of subway fire was analyzed.

(2) Through the analysis of Daegu subway fire accident in Korea, the questionnaire was designed to investigate the university students' health belief about self-help escape in subway fires. The result of the questionnaires analysis was that the seriousness of the perception of subway fire significantly affect whether the university students understand the knowledge of self-help escape.

(3) Health Belief Model was helpful to predict the psychological factors of university students and influence people's understanding of self-help escape knowledge in subway fires. The perceived serious of the consequences of subway fire accidents was increased by using health education interventions. For example, in the subway station, some multimedia should be added to bring attention to the prevention of subway fire and lectures about self-help escape knowledge could be organized in schools. When people understand the serious consequences of subway fires, they will take the initiative to learn the relevant of self-help escape knowledge about subway fires, so as to escape as much as possible when they encounter a subway fire incident.

(4) Despite a number of advantages, this study also had some limitations. The participants in this study were highly educated university students, but this study has not yet extended to the whole age of society. Moreover, the questionnaire was designed authors. Although the reliability and validity of the survey were examined before the formal investigation, it has not yet been evaluated by well-known experts. Thus, further research should be conducted with a more heterogeneous population and with larger samples to explore whether age and education are related to the health belief of self-help escape in subway fires. It is helpful to understand and evaluate the influence of the various dimensions of Health Belief Model on self-help escape knowledge of subway fires from various perspectives, so as to help spread the targeted and individualized the self-help escape knowledge of subway fires.

\section{REFERENCES}

[1] Xiao-hai Xie. Present situation and prospect of metro vehicle in global market $[\mathrm{J}]$. Foreign Locomotive \& Rolling Stock Technology, 2016, 02:1-4. (In Chinese)

[2] Ya-jun Jiang, Qi-xin Yang. Primary study on disaster prevention and rescue system $[\mathrm{J}]$. Chinese Journal of Underground Space and Engineering, 2003, 04: 427-430. (In Chinese) 
[3] Wei-wei Li, Zhen-min Tang. Analysis on metro operation accidents and study on their countermeasures [J]. China Safety Science Journal, 2004, 06:108-111. (In Chinese)

[4] Yuan-cheng Yang. A thesis submitted in partial fulfillment of the requirements for the degree of master of engineering [D].Huazhong University of Science and Technology, 2009. (In Chinese)

[5] Feng-wei Li, Xiu-li Du, Ming-hao Zhang. Statistical analysis of accidents in metro construction $[\mathrm{J}]$. Chinese Journal of Underground Space and Engineering, 2014, 02:474-479. (In Chinese)

[6] Xian-feng Zeng. Analysis and prevention of metro operation accident [J]. Science \& Technology Information, 2009, 17:163-161. (In Chinese)

[7] Gui Fu, Chun Yang, Wen-tao Yin, et al. Extended version of behavior-based accident causation"2-4"model [J]. Journal of China Coal Society, 2014, 06:994-999. (In Chinese)

[8] Gui Fu, Yun-xiao Fan, Rui-peng Tong, et al. A universal methodology for the causation analysis of accidents (4th ed) [J]. Journal of Accident Prevention, 2016, 2(1):7-12. (In Chinese)

[9] GuiFu. Safety Management [M]. Beijing, Science Press, 2013. (In Chinese)
[10] Seoul Metropolitan Rapid Transit Corporation, Facilities of SMRTC,

http: //www.smrt.co.kr/index.jsp (In Korean)

[11] Seoul Metropolitan Subway Corporation, Facilities of SMSC, http: //www.seoulsubway.co.kr/(In Korean)

[12] Cai-huan Wang, Liang-wei Geng. The history behind the fear "2.18" Daegu subway fire in Korea academic lecture record [J]. Law \& Life Orient Fire Protection, 2003, 10:52-69. (In Chinese)

[13] Champion VL, Skinner CS. The health belief model. In: Glanz K, Rimer BK, Viswanath K, eds. Health Behavior and Health Education, Theory, Research and Practice. 4th ed. New York, NY Jossey-Bass; 2008.

[14] Teamur Aghamolaei, Sedigheh Sadat Tavafian, Abdoulhossain Madani. Prediction of helmet use among Iranian motorcycle drivers: An application of the Health Belief Model and the Theory of Planned Behavior [J]. Traffic Injury Prevention, 2011, 12(3):

[15] L.J.Cronbach, Coefficient alpha and the internal structure of tests. Psychometrika, 16(1951), 297-334. 